\title{
Long-term Clinical Outcomes and Cost-Effectiveness of Full-Arch Implant-Supported Zirconia-Based and Metal-Acrylic Fixed Dental Prostheses: A Retrospective Analysis
}

\author{
Shayan Barootchi, DMD ${ }^{1} /$ Houssam Askar, BDS $1 /$ Andrea Ravidà, DDS, $\mathrm{MS}^{1} /$ \\ Jordi Gargallo-Albiol, DDS, MS, $\mathrm{PhD}^{2} /$ Suncica Travan, DDS, $\mathrm{MS}^{1} /$ Hom-Lay Wang, DDS, MS, $\mathrm{PhD}^{3}$
}

\begin{abstract}
Purpose: To provide a long-term comparison of metal-acrylic and zirconia implant-supported fixed complete dental prostheses. Materials and Methods: Patients treated with a metal-acrylic or zirconia fixed implant prosthesis with a minimum 5-year follow-up were included. All complications were registered, along with events such as peri-implantitis and implant failure. Survival and all costs associated with the prostheses were assessed to provide an overall evaluation of each type of fixed implant prosthesis protocol. Results: Seventy-four rehabilitated arches (43 metal-acrylic, 31 zirconia, mean follow-up: $8.7 \pm 3.37$ years) were included. Delayed complications accompanied the metal-acrylic prostheses more frequently. In both groups, single tooth chipping/fracture was the most prominent minor complication, and incidence of multiple teeth and framework fracture was the most frequent major complication. Zirconia fixed implant prostheses demonstrated higher prosthetic survival rates than the metal-acrylic prostheses $(93.7 \% \pm 5.5 \%$ at 5 years vs $83.0 \% \pm 11.1 \%)$. No difference was observed for peri-implantitis or implant failure. The initial cost for zirconia prosthesis fabrication was significantly higher than metal-acrylic hybrids (an estimated difference of $\$ 7,829[P<.001])$; however, due to reduced complication rates for the zirconia fixed implant prosthesis, maintenance and treatment for complications did not greatly differ between groups. Conclusion: Within the limitations, zirconia fixed implant prostheses presented higher initial costs than metal-acrylic hybrids, however, with satisfactory outcomes, reduction of overall complications, and superior survival rates. INT J Oral MaXilLofac ImPLANTS 2020;35:395-405. doi: 10.11607/jomi.7833
\end{abstract}

Keywords: $C A D / C A M$, ceramics, dental implants, fixed implant prostheses, zirconia

${ }^{1}$ Graduate Periodontics, Department of Periodontics and Oral Medicine, University of Michigan School of Dentistry, Ann Arbor, Michigan, USA.

${ }^{2}$ Associate Professor and Director of the International Master in Oral Surgery, Oral and Maxillofacial Surgery Department, Universitat Internacional de Catalunya, Barcelona, Spain; Research Scholar, Department of Periodontics and Oral Medicine, University of Michigan School of Dentistry, Ann Arbor, Michigan, USA.

${ }^{3}$ Professor and Director of Graduate Periodontics, Department of Periodontics and Oral Medicine, University of Michigan School of Dentistry, Ann Arbor, Michigan, USA.

Correspondence to: Dr Hom-Lay Wang, Department of Periodontics and Oral Medicine, University of Michigan School of Dentistry, 1011 North University Avenue, Ann Arbor, Ml 48109-1078, USA. Fax: (734) 936-0374.

Email: homlay@umich.edu

Submitted May 13, 2019; accepted July 15, 2019.

@2020 by Quintessence Publishing Co Inc.
The continuing population growth worldwide and the increase in the proportion of older individuals are leading to a rise in the need for the treatment of edentulism. ${ }^{1}$ With the establishment of high success rates and the advantages that implant therapy offers over conventional denture therapy, implantsupported fixed complete dental prostheses have increasingly become popular for rehabilitations of edentulous arches, particularly in younger adults and those unable to cope with tissue-supported prostheses. ${ }^{2-4}$ Some of the advantages provided by the fixed implant prostheses are comfort, aid in alveolar bone preservation, and substantial improvements in prosthetic function, adaptation, and stability. ${ }^{5-8}$ Supporting this view, some authors have argued that a fixed implant prosthesis should be considered as the standard of care, especially in mandibular arches where limited osteomucosal support can jeopardize the retention of a conventional denture. ${ }^{8}$ 
Metal-acrylic hybrids are among the most-studied treatment protocols for restoration of an edentulous arch with a fixed implant prosthesis. Long track records of these hybrids have presented simplicity in their use, reduced cost, and ease in reparability. ${ }^{9-11}$ However, their relatively high complication rates for denture teeth debonding, veneered acrylic fracture, and screw/ abutment loosening are time-consuming for both patients and clinicians. ${ }^{10,12-16}$ Fracture or wear of the reconstruction materials in resin-based suprastructure prostheses should be considered a predictable risk when considering these types of restorations. ${ }^{10}$ These concerns can cause inconveniences and lead to financial challenges for both the patient and the restorative team, vastly influencing their decision in choosing the appropriate prosthesis.

Zirconia has been used in dentistry for more than a decade with different indications, such as endodontic dowels, dental implants, implant abutments, and crowns, ${ }^{17}$ and zirconia-based materials have gained considerable interest in the fabrication of fixed complete dentures to potentially address some of the problems that clinicians and patients previously encountered with the metal-acrylic hybrids. Additionally, zirconia has gained popularity as an alternative to metal frameworks in the fabrication of fixed implantsupported prostheses for its high biocompatibility, lower accumulation of plaque and bacteria on its surface, high flexural strength, and reduced staining compared with acrylic resins. ${ }^{12,18,19}$

The computer-aided design/computer-aided manufacturing (CAD/CAM) routinely used in fabricating a zirconia prosthesis allows for a superior fit of the prosthesis compared with the conventional metal-acrylic hybrids. ${ }^{12}$ Among the advantages of this technology are the ability to predictably fabricate a full-arch prosthesis entirely in the virtual world while automatically storing the designs ${ }^{20}$; high biocompatibility, superior precision design, and higher accuracy. ${ }^{20-23}$ However, challenges have also been associated with zirconia prostheses, which include: heavier weight compared with metal-acrylic prostheses ${ }^{12}$ and difficulty in adjusting and polishing the framework. ${ }^{24}$ Additionally, as insufficient long-term evidence currently exists on the clinical efficacy of implant-supported zirconia prostheses, ${ }^{12,25}$ caution in regard to extensive implant-supported zirconia frameworks should be exercised.

Furthermore, in addition to accuracy and clinical predictability, it is also critical for any new technology to be proven cost-effective, particularly in the long term. Therefore, the aim of the present retrospective study was to identify the incidence of biologic and prosthetic complications associated with screw-retained metal-acrylic and zirconia fixed implant-supported prostheses, to evaluate the cost-effectiveness of the two treatment modalities, and lastly, to compare the two treatment protocols, investigating their clinical outcomes.

\section{MATERIALS AND METHODS}

The present research was designed and performed by abiding to the principles presented in the Helsinki Declaration (1975), as revised in 2000, for biomedical research involving human subjects. The research protocol was approved by the Institutional Review Board (IRB) for Human Studies, School of Dentistry, University of Michigan, Ann Arbor, Michigan, USA (HUM00114382), and the article was prepared in compliance with the STROBE guidelines (Appendix 1 ; see Appendixes in online version of this article at quintpub.com).

This retrospective study included all patients treated with metal-acrylic and zirconia fixed implant prostheses at the School of Dentistry, University of Michigan. All paper and digital patient files treated with implant-supported metal-acrylic and zirconia fixed implant prostheses were carefully scanned and analyzed by two authors (S.B., H.A.). During each stage, an expert (J.G.) was consulted in case of a disagreement. The inclusion and exclusion criteria that were applied are described as follows:

\section{Inclusion criteria:}

- Patients treated with full-arch metal-acrylic and zirconia fixed implant prostheses with a documented follow-up of $\geq 5$ years

- Full-arch cases where all implants were placed within the same surgical procedure

- Presence of opposing occlusion

- Active patients enrolled in a maintenance schedule based on their individual needs and receiving at least one maintenance visit per year

\section{Exclusion criteria:}

- Subjects treated with a removable overdenture, an implant-retained overdenture, or porcelain-fusedto-metal restorations

- Inaccessible files due to any reason (deceased, bad debt) or charts with incomplete or unusable data

- Patients treated or maintained outside the University of Michigan School of Dentistry

- Prostheses supported by four implants

- Medically compromised patients (any past records of uncontrolled diabetes, radiation and/or chemotherapy treatment, psychologic problems), and severe bruxism cases (if stated or self-reported) 


\section{Data Collection and Classification}

Within the review period, a screening of all full-arch fixed implant-supported prosthesis rehabilitations at the University of Michigan was performed, and the selected cases were divided into two groups depending on the type of prosthesis (metal-acrylic or zirconia). Patient information, such as age (at the time of surgery), sex, history of smoking ( $\geq 1$ cigarette/day), diabetes (verified by checking full medical records), and history of periodontal disease were obtained along with other significant and correlated past medical diagnoses. History of periodontal disease, determined by reviewing the periodontal chart, was defined as the presence of at least four sites with clinical attachment loss $(C A L) \geq 3 \mathrm{~mm}$ and/or patients who had received professional treatment for periodontitis (scaling and root planing). ${ }^{26,27}$ Additional data including time of implant placement, prosthetic loading protocol, number of implants and their characteristics, bone augmentation, flap procedures, and the type of prosthesis and/or the dentition in the opposing arches were registered.

The surgical, prosthodontic, and laboratory procedures that were followed are described in the Appendix 2 .

\section{Complications}

All incidences of technical and biologic complications with their subsequent management were recorded at each visit and at the time of occurrence, and for comparison between the metal-acrylic and zirconia fixed implant prostheses, all possible complications were classified as follows.

Prosthetic Complications. All prosthetic complications, such as (1) fracture, dislodgment, chipping, or replacement of prosthetic teeth; (2) prosthesis fractures; (3) fracture of bars/frameworks; (4) loosening of abutment screws; and (5) replacement of prostheses were recorded and grouped into the following:

- Early or delayed prosthetic complications: Early prosthetic complications were defined as those occurring within 1 year of prosthetic loading, whereas delayed prosthetic complications were those that occurred 1 year after prosthetic placement.

- Minor and major prosthetic complications, and catastrophic failures: Minor complications were those that could be managed intraorally, and/ or fixed chairside by the clinician within 24 hours of presentation, not requiring further laboratory processing or replacement. Major complications were ones that could not be managed or repaired chairside and required more extensive approaches (> 24 hours) and/or laboratory repair for their treatment. Catastrophic failure was the sudden and total failure of the prosthesis along with the dental implants from which recovery was impossible.

Biologic Complications. Biologic complications included the following:

- Denture-induced soft tissue complications, such as hyperplasia, prosthesis-induced ulcers, or pain were categorized into this group.

- Peri-implantitis and implant failure: The definition proposed by the 8th European Workshop on Periodontology in 2011 was adopted for periimplantitis, ${ }^{28}$ where clinical inflammation combined with the radiographic marginal bone loss of more than $2 \mathrm{~mm}$ after bone remodeling was indicative of the disease. The level of the periimplant marginal bone was measured at baseline (after placement of the definitive prosthesis) and the final follow-up visit via calibrating the available periapical and panoramic radiographs using digital software (ImageJ, U. S. National Institutes of Health). Calibration was performed by the known length and/or diameter of each implant. All radiographic analyses were performed by one author (S.B.) and coded as a binary outcome of "yes" or "no" in a preformulated spreadsheet. In case of uncertainty, an expert reviewer (J.G.) was consulted for reassessing the radiographs. Additionally, if the patient had received treatment for peri-implantitis, that was also indicative of the disease. The presence of peri-implantitis was assessed and recorded per patient, and per individual implant. The incidence of peri-implantitis for an implant was recorded as a binary outcome ( 0 for a healthy implant, 1 for an implant showing signs of disease), and the percentage of diseased implants was calculated. Similar values were assigned to patients based on the presentation of peri-implantitis surrounding any of the implants ( 0 for a patient without any diseased implants, 1 if a patient showed signs of $\geq 1$ diseased implant). Failure of an implant was defined in case of a lost, removed, or fractured implant and was calculated for each implant individually and then per patient, with the same methods described for peri-implantitis. ${ }^{29}$

\section{Cost Analysis}

The cost analysis was aimed at assessing all costs for diagnosis, repair, laboratory work, and maintenance as previously performed. ${ }^{30}$ In summary, a standardized average for the cost relating to all performed procedures was determined throughout the entire follow-up for all prostheses and categorized as the initial cost (for implant placement procedures and prosthesis rehabilitation), the cost for complications (expenses related to 
management of complications), and the total cost (the sum of the initial cost and the complication management). Detailed explanations on this analysis are presented in Appendix 2.

\section{Statistical Analyses}

Descriptive statistics were used to present data on complications and failures for each group. The demographic profile and clinical characteristics of the included sample were compared using: (1) $t$ test analyses ( $t$ ); (2) $\mathrm{Chi}^{2}$ homogeneity tests $\left(\mathrm{Chi}^{2}\right)$; (3) Fisher's exact test (Fis); and (4) Mann-Whitney test (MW). For descriptive purposes, every edentulous arch corresponded to one case of an implant-supported fixed dental prosthesis.

Survival analysis was performed for the metal-acrylic and zirconia prostheses with the Kaplan-Meier function, estimating the cumulative survival rate (CSR) with $95 \%$ confidence intervals (Cl). Survival was defined as the prosthesis remaining functional without replacement. Prostheses that needed to be refabricated for any reason were considered as failures. The Log Rank (Mantel-Cox) test was used for overall comparison of the survival curves.

The association between prosthetic complications across both study groups was analyzed using (1) descriptive analyses: number of cases ( $n$ ), percentages (\%), and mean \pm standard deviation (SD); (2) a simple binary logistic regression model for each type of complication: estimation of unadjusted odds ratio (OR); and (3) a Mann-Whitney test for homogeneity test of distributions in continuous variables.

The probability of peri-implantitis and implant failure in both groups was calculated using a generalized estimation equation (GEE): estimation of odds ratio (OR) adjusted by smoking, history of periodontitis, and follow-up time. Cost analyses were performed using a generalized linear model: estimation of coefficients was adjusted by the number of implants and follow-up time (years).

\section{RESULTS}

\section{Descriptive Analyses and Demographic Profiles}

Three hundred fifty-two cases were initially identified based on the primary search on full-arch restorations. Among those, 278 were excluded due to the following reasons: (1) 119 cases with $<5$ years follow-up; (2) 67 implant-retained overdentures; (3) 24 full-arch or multiple-unit tooth-supported dental prostheses; (4) 22 prostheses supported by four implants; (5) 15 files without or with unusable radiographs; (6) 9 cases with missing/unavailable postsurgical data; (7) 8 cases where the definitive prosthesis was placed or completed outside the University of Michigan; (8) 7 deceased patients; and (9) 7 unclear files with missing or incomplete data.

Finally, 74 full-arch prostheses (amounting to 56 patients, mean age of $52.9 \pm 12.9$ years) were included. Thirty-five patients had been treated with 43 metalacrylic prostheses, while 21 patients had received 31 zirconia fixed implant prostheses. No statistically significant differences were observed with regard to age $(P=.7)$ and sex $(P=.3)$ between the metal-acrylic and zirconia groups.

Overall, 452 implants ( 252 in the metal-acrylic and 200 in the zirconia group) were included in the present study; $40.5 \%$ of the prostheses were restored with 6 implants (19 in metal-acrylic, 11 in the zirconia group); $33.9 \%$ of the prostheses were restored with 5 implants (18 in metal-acrylic, 17 in zirconia); $9.45 \%$ of the prostheses were restored with 7 implants ( 2 in metal-acrylic, 5 in zirconia), and $17.56 \%$ of the prostheses were restored with 8 implants ( 5 in metal-acrylic, 8 in zirconia). The average follow-up period was $104.7 \pm 40.5$ months for all the prostheses $(118 \pm 45.8$ months for metal-acrylic, $90.9 \pm 23.49$ months for zirconia), with a median follow-up of 8 years.

\section{Clinical Characteristics Among Groups}

The difference in the follow-up time was significantly higher in the metal-acrylic group $(P<.01)$. Clinical parameters such as implant loading (immediate vs delayed) and flapless surgery were significantly more associated with the zirconia restorations $(P<.01$ and $P<.05$, respectively). Conversely, the number of smokers, diabetics, patients with a history of periodontitis, and the location of the prosthesis (maxilla or mandible) were found not to be statistically different between groups $(P>.05)$. The opposing arches of the metal-acrylic fixed implant prostheses consisted of 22 metal-acrylic hybrid prostheses, 6 conventional complete dentures, 1 implant-retained overdenture, 13 cases with a combination of teeth and crowns, and 1 removable partial denture. The opposing arches for the zirconia fixed implant prostheses included $28 \mathrm{im}$ plant-supported zirconia fixed prostheses, and 3 arches with a combination of teeth, crowns, and implants. The patient demographics and clinical characteristics are presented in Table 1.

\section{Prosthetic Complications}

A thorough overview of the prosthetic complications for both groups is presented in Tables A1 and A2 in Appendix 2 .

\section{Early and Delayed Complications}

The incidence of early complications was not significantly different among both groups (23\% of the 


\begin{tabular}{|c|c|c|c|}
\hline & \multicolumn{3}{|c|}{ Fixed implant prosthesis group } \\
\hline & Metal-acrylic $(n=43)(\mathrm{impl}=252)$ & Zirconia $(n=31)(i m p l=200)$ & $P$ value (test) \\
\hline Follow-up (mo) & $114.6 \pm 47.1$ & $86.35 \pm 18.31$ & $.006 *(t)$ \\
\hline Age $(y)$ & $58.8 \pm 13.3$ & $59.7 \pm 12.6$ & $.765(t)$ \\
\hline Male & $23(53.5 \%)$ & $20(64.5 \%)$ & $.343\left(\mathrm{Chi}^{2}\right)$ \\
\hline Smokers & $4(9.3 \%)$ & $8(25.8 \%)$ & $.057\left(\mathrm{Chi}^{2}\right)$ \\
\hline Diabetics & $5(11.6 \%)$ & $2(6.5 \%)$ & .692 (Fis) \\
\hline History of periodontitis & 9 (20.9\%) & $13(41.9 \%)$ & $.051\left(\mathrm{Chi}^{2}\right)$ \\
\hline Maxillary rehabilitations & $22(51.2 \%)$ & $18(58.1 \%)$ & $.557\left(\mathrm{Chi}^{2}\right)$ \\
\hline Immediate implants & $4(9.3 \%)$ & $0(0.0 \%)$ & .135 (Fis) \\
\hline Immediate loading & $21(48.8 \%)$ & $1(3.2 \%)$ & $<.01 *\left(\mathrm{Chi}^{2}\right)$ \\
\hline Open flap & $23(53.5 \%)$ & $24(77.4 \%)$ & $.035 *\left(\mathrm{Chi}^{2}\right)$ \\
\hline Bone augmentation & $14(32.6 \%)$ & $11(35.5 \%)$ & $.793\left(\mathrm{Chi}^{2}\right)$ \\
\hline No. of maintenance visits & $9.9 \pm 8.8$ & $6.0 \pm 3.1$ & $.291(\mathrm{MW})$ \\
\hline Implant failure (patient) & $10(23.3 \%)$ & $6(19.4 \%)$ & $.688\left(\mathrm{Chi}^{2}\right)$ \\
\hline Implant failure (implant) & 32 (12.7\%) & 19 (9.5\%) & $.303\left(\mathrm{Chi}^{2}\right)$ \\
\hline
\end{tabular}

Data are expressed in mean \pm SD or percentage (\%).

$\mathrm{Chi}^{2}=\mathrm{Chi}^{2}$ homogeneity tests; Fis = Fisher's exact test; $\mathrm{MW}=$ Mann-Whitney tests; $\mathrm{n}=$ number of prostheses; impl = number of implants.*Statistically significant association.

\begin{tabular}{|c|c|c|c|c|c|}
\hline \multirow{3}{*}{\multicolumn{2}{|c|}{ Table 2}} & nplications and & tistical Analy & Between Both & oups of \\
\hline & & \multicolumn{2}{|c|}{ Group } & \multirow[b]{2}{*}{ OR (95\% CI) } & \multirow[b]{2}{*}{$P$ value } \\
\hline & & Metal-acrylic $(n=43)$ & Zirconia $(n=31)$ & & \\
\hline \multicolumn{2}{|c|}{ Minor prosthetic complications } & $31(72.1)$ & $19(61.3)$ & $0.61(0.23-1.64)$ & .329 \\
\hline \multicolumn{2}{|c|}{ Total minor prosthetic complications } & $3.4 \pm 4.2$ & $1.7 \pm 2.7$ & & $.051(\mathrm{MW})$ \\
\hline \multicolumn{2}{|c|}{ Major prosthetic complications } & $18(41.9)$ & $8(25.8)$ & $0.48(0.18-1.32)$ & .157 \\
\hline \multicolumn{2}{|c|}{ Total major prosthetic complications } & $0.8 \pm 1.2$ & $0.5 \pm 1.0$ & & $.160(\mathrm{MW})$ \\
\hline \multicolumn{2}{|c|}{ Catastrophic failure } & $2(4.7)$ & $2(6.5)$ & $1.41(0.19-10.6)$ & .736 \\
\hline \multicolumn{2}{|c|}{ Denture-induced soft tissue complications } & $12(27.9)$ & $4(12.9)$ & $2.16(0.63-7.34)$ & .216 \\
\hline \multicolumn{2}{|c|}{ Early complications } & $10(23.3)$ & $10(32.3)$ & $1.57(0.56-4.42)$ & .391 \\
\hline \multicolumn{2}{|c|}{ Delayed complications } & 31 (72.1) & $16(51.6)$ & $0.41(0.16-1.09)$ & .074 \\
\hline
\end{tabular}

Data are expressed in mean $\pm \mathrm{SD}$, or percentage (\%).

$\mathrm{MW}=$ Mann-Whitney tests; $\mathrm{n}=$ number of prostheses.

metal-acrylic prostheses, and $32.3 \%$ of the zirconia fixed implant prostheses, $\mathrm{OR}=1.57, P=.391$ ). Additionally, occurrence of delayed complications similarly lacked statistical significance between groups $(P>.05)$. However, a trend was observed in the rate of delayed complications that affected $72.1 \%$ of the metal-acrylic prostheses and $51.6 \%$ of the zirconia, and it was found that a zirconia structure reduced the risk for delayed complications up to $59 \%$ when compared with metal-acrylic prosthesis, $\mathrm{OR}=0.41$ $(P=.074)$ (Table 2).

\section{Minor and Major Complications, and Catastrophic Failure}

Among both investigated groups, minor complications were the most prominent (67.6\%). Single tooth fracture/dislodgment in the metal-acrylic group (94 times in 22 prostheses) and single tooth chipping/ fracture in the zirconia prostheses (36 times in 9 prostheses) were the most common events. Next were major complications (35.1\%), with multiple teeth fracture (requiring laboratory processing) as the most prevalent in both groups (40 times in 17 metal-acrylic, 

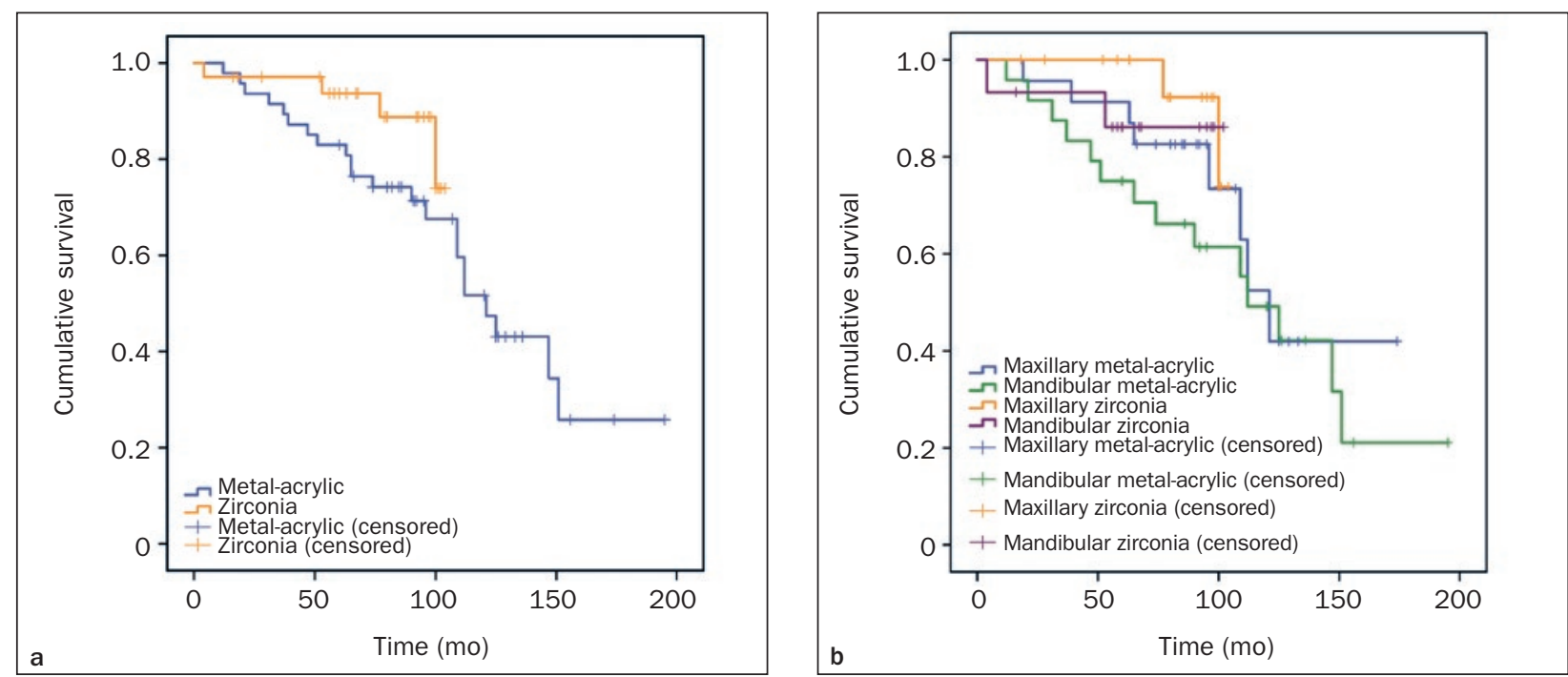

Fig 1 Survival plots based on the Kaplan-Meier analysis. (a) Overall survival of metal-acrylic and zirconia fixed implant prostheses. (b) Survival analysis based on different arches for both metal-acrylic, and zirconia fixed implant prostheses.

and 17 times in 4 zirconia fixed implant prostheses). Lastly, catastrophic failures were observed two times in both groups $(P>.05)$. The number of prostheses affected by minor complications was slightly higher in the metal-acrylic group than the zirconia group (72.1\% and $61.3 \%, P=.329)$, exhibiting a mean value of 3.4 vs 1.7 minor complications per case, respectively $(P=.05)$. Major complications were more prominent in the metal-acrylic group as well $(41.9 \%$ vs $25.8 \%)$. However, after adjusting for the different follow-ups, this difference lacked statistical significance $(P=.15)$. An overview of all complications and implant failures that occurred with respect to time is displayed in Table A3 in Appendix 2.

\section{Prosthesis Survival Rate}

The estimated cumulative survival rate of zirconia and metal-acrylic prostheses at 5 years was $93.7 \% \pm 5.5 \%$ vs $83.0 \% \pm 11.1 \%$, respectively. At 8 years, the estimated rate for zirconia prostheses was $88 \% \pm 8.8 \%$ vs $67.6 \%$ $\pm 14.8 \%$ for the metal-acrylic hybrids (which became $51.7 \% \pm 12.1 \%$ at the 10 -year follow-up) (Fig 1a). The Log Rank (Mantel-Cox) test confirmed the nonequality in survival distribution among the fixed implant prosthesis groups $(P=.046)$. Moreover, rehabilitation on maxillary arches presented with higher survival rates for both types of prostheses (mean survival time of 125.7 months [95\% Cl $(101.82,149.74)])$ for maxillary metal-acrylic vs 113.5 months (95\% Cl [86.79, 140.23]) for mandibular metal-acrylic hybrids; and mean survival time of 101.185 (95\% Cl [97.175, 105.195]) for maxillary vs 91.94 (95\% Cl [78.33, 105.195]) for mandibular zirconia fixed implant prostheses (Fig 1b).

\section{Biologic Complications}

Prosthesis-Induced Biologic Complications. Prevalence of biologic complications related to the prosthesis was relatively similar between both groups $(P>.05)$. In treated arches with metal-acrylic fixed implant prostheses, there were four instances of ulceration, two cases of epulis fissuratum (caused by instability and looseness of the prosthesis), four reports of pain and soreness associated with the acrylic, one case in which the denture had been causing obstruction of the Stenson's duct and needed refabrication, and a single event of candidiasis (treated with antifungal medication). In the zirconia group, two patients presented with oral candidiasis (treated with antifungal medications and steroids), one hyperplasia, and one case of gingival overgrowth (treated with gingivectomy).

\section{Peri-implantitis}

The prevalence of peri-implantitis for both study groups is presented in detail (Appendix 5). A GEE, adjusted for smoking, history of periodontitis, and follow-up time demonstrated a similar incidence of peri-implantitis within both groups per patient $(P=.5)$ and per implant $(P=.9)$. However, despite the prosthetic restoration, an implant placed in a patient with a history of periodontal disease increased the risk of peri-implantitis up to four times compared with an implant placed in a periodontally healthy patient $(\mathrm{OR}=4.10, P=.003)$.

\section{Implant Failure}

At the patient level, $23.3 \%$ of subjects experienced implant failure in the metal-acrylic and $19.4 \%$ in the zirconia group $(P=.68)$. When adjusted for smoking, 

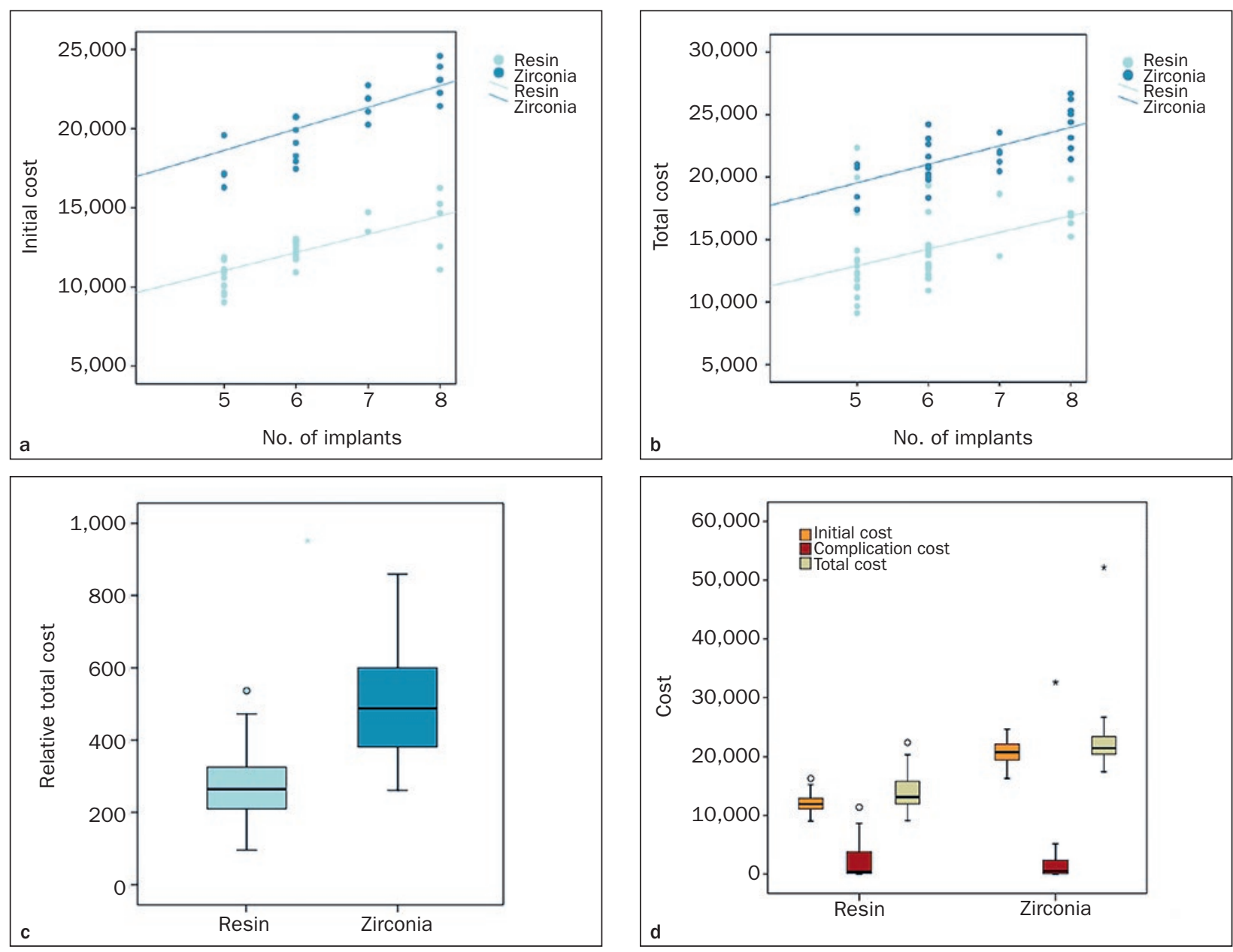

Fig 2 Projection of cost expenditure through the overall follow-up time for metal-acrylic and zirconia prostheses. (a) Initial cost based on the number of implants utilized to support the framework. (b) The total computed cost according to the number of implants. (c) The relative total cost per group. (d) An overview of all computed costs for each restoration.

history of periodontitis, and follow-up, no statistical differences could be seen between groups $(P=.19)$. At the implant level, no statistically significant differences were observed between the groups after adjusting for possible confounding factors $(P=.26)$. Nevertheless, it was found that an implant placed in a patient with a history of periodontitis multiplies the risk of failure by 4.3 times $(\mathrm{OR}=4.37, P=.01)$.

\section{Cost Analyses}

Regression analyses illustrated that for the same number of implants, a zirconia prosthesis required a significantly higher initial cost, on average an additional $\$ 7,829$ compared with the metal-acrylic fixed implant prosthesis $(P<.001)$. Additionally, when adjusted for the longer follow-up time in metal-acrylic hybrids, there were no differences in the average cost of complications in patients treated with a metal-acrylic or zirconia prosthesis $(P=.319)$.
The total cost is affected by this initial cost difference, which on average was approximately $\$ 14,000$ for the metal-acrylic hybrid group, and approximately $\$ 22,000$ for the zirconia group $(P<.001)$. Lastly, regression analysis concluded that the average cost per single implant, per every year of follow-up, was $\$ 292.3$ $\pm \$ 139.2$ in the metal-acrylic, and \$485.2 \pm \$141.9 in the zirconia group $(P<.01)$ (Fig 2). Details regarding the initial cost for the prostheses in each group, the expenses associated with management of the complications, and the total costs are presented in Table A4 of Appendix 2.

\section{DISCUSSION}

The CAD/CAM-fabricated zirconia frameworks were introduced to overcome the mechanical drawbacks of earlier all-ceramic systems. ${ }^{31-35}$ The increasing demand 
for metal-free restorations with enhanced translucency has led to recent developments of biocompatible ceramics. These ceramics, while slowing the process of wear (typical of metal-acrylic prostheses), provide esthetic advantages to the opaque appearance of the absolute monolithic zirconia. The aim of the present study was, therefore, to retrospectively evaluate the overall characteristics, complications, and survival rate of the one-piece milled zirconia framework bars with ceramic restorations, and compare them with the traditional metal-acrylic hybrids. ${ }^{10,36,37}$

Since a definitive consensus in the literature regarding description of technical events has not been established yet, ${ }^{38}$ the authors of the present study proposed their own categories to facilitate the comparison between the metal-acrylic and zirconia fixed implant prostheses. Minor complications were the most frequently recorded event among both prosthesis groups, presenting mainly as tooth chipping/ fracture in both the metal-acrylic and zirconia prostheses at rates of $51 \%$ and $29 \%$, respectively. Papaspyridakos and Lal, in a 4-year retrospective case series, stated that porcelain fracture/chipping was the most frequent complication in zirconia fixed implant prostheses, yielding a $31 \%$ ceramic chipping rate. ${ }^{25}$ Moreover, results from a 3-year prospective study on mandibular cement-retained implant-supported zirconia prostheses also reported a high chipping rate of $34 \%{ }^{39}$ It is worth mentioning that the longer follow-up of zirconia fixed implant prostheses in the present study, and the similar but not identical design of the prosthesis, may inhibit an exact comparison of all the findings of the present study to that of other publications. Furthermore, it should be noted that the ceramic thickness used for fabrication of the included prostheses was $1 \mathrm{~mm}$ in the anterior region and at least $1.5 \mathrm{~mm}$ in the posterior areas, which had been due to the lack of proprioception around the implants and the inclination toward providing increased bulk, aiming to reduce ceramic fractures.

Regarding metal-acrylic fixed implant prostheses, it was noticed in the present study that 22 metal-acrylic hybrid prostheses (51\%) were affected by fracture of denture teeth in an average period of almost 10 years. This high incidence can also be observed in another study, where Purcell and coworkers reported 28 fractures of denture teeth in 46 metal-acrylic hybrids in an average recall time of 7.9 years. ${ }^{14}$ In addition, Göthberg and coworkers concluded that in 3 years, approximately $23 \%$ of patients with hybrid prostheses experienced fracture of the resin matrix, including the acrylic teeth. ${ }^{40}$ Interestingly, different authors possess different perceptions concerning tooth fracture episodes, as many studies have acknowledged tooth fracture and tooth wear as major complications for the metal-acrylic hybrids, ${ }^{40,41}$ while others have dismissed them as easily fixable and noncatastrophic. ${ }^{42,43}$

In the comparison between the metal-acrylic and zirconia fixed implant prostheses, a higher trend was observed for complications in the metal-acrylic group, despite lacking statistical significance. Furthermore, a direct correlation between the follow-up time and complication rates was also found. A recent retrospective analysis directly comparing four types of full-arch restorations (including zirconia fixed implant prostheses, porcelain-veneered zirconia, metal-acrylic hybrids, and retrievable crowns on titanium frameworks) found that chipping and fracturing of teeth was the mostreported complication among all treatment groups, after posterior wear of the prostheses. ${ }^{44}$ Additionally, similar to the observations of the present study, metal-acrylic hybrids experienced significantly greater complications than zirconia prostheses but less than porcelain-veneered zirconia and retrievable crown fixed implant prostheses. The authors stated that all the complications in the retrievable crown prostheses were associated with the porcelain-fused-to-metal restorations and that the relatively high complication rate $(50 \%)$ associated with porcelain-veneered zirconia prostheses may have stemmed from the patients' and providers' desire in the selection of laminated zirconia due to its esthetic appeal. It is worth noting that in the present study, the prostheses consisted of individual ceramic crowns that, when compared with that of the previous study, presented with fewer complications in addition to a longer follow-up time. Additionally, Maló and colleagues had emphasized a significant increase in complication rates from 5 to 10 years in implantsupported fixed prostheses. ${ }^{45}$

The importance of the opposing dentition in regard to prosthetic complications and failures has been previously addressed in many studies. ${ }^{14,45-47}$ A correlation with metal-ceramic and zirconia prostheses in the opposing arch and increased prosthetic complications has been found. ${ }^{45}$ Conversely, a trend toward lower prosthetic complications with opposing conventional metal-acrylic hybrids has also been demonstrated. ${ }^{46}$ In the present study, the majority of the zirconia fixed implant prostheses were opposed by zirconia-based restorations (90.3\%), and most of the metal-acrylic hybrids were opposed by acrylic-based restorations (67.1\%). However, it was observed that the metalacrylic prostheses encountered more complications compared with the zirconia group, which were mostly in occlusion with zirconia fixed implant prostheses.

An emerging concern in the evolving field of dental implants is the prevalence of peri-implantitis. The present study failed to find a significant difference between either prosthetic type when confounding variables (difference in follow-up time, number of smokers, 
patients with past history of periodontitis) were controlled. Nevertheless, a history of periodontitis was recognized as an important prognostic factor for future peri-implantitis and implant failure, increasing the risk of peri-implantitis four times compared with a periodontally healthy patient. This matches the results of Karoussis et al, who observed that patients with a history of periodontitis are more at risk of being affected by peri-implant mucositis and peri-implantitis. ${ }^{48}$ Thus, a careful assessment of the patients' periodontal status is imperative before planning an implant-supported prosthesis, and patients should be informed individually of the risk of peri-implantitis and implant failure in case of a previous history of periodontitis.

A crucial element of this project was assessing the long-term survival of each treatment modality. The survival criteria implemented in the present study reflect the functionality of the prosthesis, without the need for substitution. In the zirconia group, two events of framework fracture, and two catastrophic failures, resulted in failure of the prostheses. Higher survival rates can be seen in the literature; Papaspyridakos and Lal reported $100 \%$ survival of zirconia prostheses in function, ${ }^{25}$ and Kolgeci et al, in a case series, reported a survival rate of $96.4 \%$ at 5 years. ${ }^{49} \mathrm{~A}$ shorter followup (4 years) in the former, ${ }^{25}$ and a combination of different fixed prostheses (single, partial, full-arch dentures) in the latter, ${ }^{49}$ may have contributed to slightly higher rates. Conversely, a 12-month prospective clinical study that enrolled 17 patients reported a survival rate of $88 \% .{ }^{20}$ In the metal-acrylic group of the present study, wear of the prostheses was the main contributor of prosthetic failure, followed by framework fracture and a few cases of multiple denture teeth fractures that significantly reduced the survival rates $(83.0 \% \pm 11.1 \%$ at 5 years, and $51.7 \% \pm 12.1 \%$ at 10 years). In a retrospective study, Priest et al stated that the replacement of the hybrid dentures in a private practice was a frequent event due to the common wear. ${ }^{15}$ However, data gathered retrospectively from another private practice led to a higher survival rate of $91 \%$ at 5 years for metalacrylic hybrids. ${ }^{50}$

One of the virtues of having an extensive follow-up for both the metal-acrylic and zirconia fixed implant prostheses is the possibility to compare the expenses associated with their long-term function. To the best of the authors' knowledge, there are no other studies comparing the cost of both treatments; therefore, a direct comparison to the literature is not possible. However, it is apparent that using individualized porcelain crowns over milled zirconia frameworks is associated with higher fees than conventional metal-acrylic prostheses. As demonstrated by the results, an additional fee of $\$ 7,829$ accompanied the zirconia treatment protocol used in the present study. This initial added cost (due to the nature of the materials, CAD/CAM technology, increased laboratory fees) is the determinant factor for the overall more expensive price of the zirconia fixed implant prosthesis. As shown in the results of the present study, the expenses associated with the maintenance of prostheses and fees toward complication handling are relatively similar among both treatment groups $(\$ 2,041$ vs $\$ 2,185)$. This lack of a price difference for treating complications, despite the higher costs related to zirconia and ceramic materials, can be due to the documented decrease in delayed complications (up to 59\%) and a significant decline in the risk of prosthetic failure that accompanies the zirconia frameworks. Therefore, the main disadvantage of the zirconia prostheses compared with the metal-acrylic hybrids (the higher cost of the milled zirconium prosthesis) is ultimately minimized by the lower tendency of complications.

The limitations of this study pertain to the different follow-up time (approximately 2 years) and sample size among the metal-acrylic and zirconia groups, which can both be attributed to the retrospective nature of the research. To the authors' knowledge, studies assessing the long-term ( $>5$ years) follow-up of milled zirconia prostheses with single crowns are rare in the literature, and this is the first study comparing and reporting their cost-effectiveness with that of the more conventional metal-acrylic hybrids. With this in mind, it is acknowledged that the esthetic appearance, the occlusal scheme, and the subjective patient-reported outcomes are important factors that could not be analyzed.

The zirconia prostheses seem promising, but not without technical complications. Indeed, enhanced predictability of this treatment may benefit from the continuing advancements in digital workflow and design. While the initial cost of the metal-acrylic prostheses is significantly lower than the zirconia, due to fewer overall complications for the zirconia prostheses, the overall maintenance of the prostheses and the treatment of those complications do not vary greatly among the two protocols. The metal-acrylic hybrids seem cost-effective; however, the survival of these hybrids significantly declines after 5 years in function, and care should be taken in treating patients with a past history of periodontitis. Additional comparative clinical studies are needed to verify the results of the present study.

\section{CONCLUSIONS}

Within the limitations, zirconia fixed implant prostheses presented higher initial costs than metal-acrylic hybrids, however, with satisfactory outcomes, reduction of overall complications, and superior survival rates. 


\section{ACKNOWLEDGMENTS}

The authors do not have any financial interests either directly or indirectly in the companies whose materials were utilized in this study. This paper was partially supported by the University of Michigan Periodontal Graduate Student Research Fund. The authors reported no conflicts of interest related to study.

\section{REFERENCES}

1. Douglass CW, Shih A, Ostry L. Will there be a need for complete dentures in the United States in 2020? J Prosthet Dent 2002;87:5-8.

2. Askar H, Gianiflippo RD, Ravida A, Tattan M, Majzoub J, Wang HL. Incidence and severity of postoperative complications following oral, periodontal, and implant surgeries: A retrospective study. J Periodontol 2019;90:1270-1278.

3. Ravidà A, Barootchi S, Askar H, Suárez-López Del Amo F, Tavelli L, Wang HL. Long-term effectiveness of extra-short $(\leq 6 \mathrm{~mm})$ dental implants: A systematic review. Int J Oral Maxillofac Implants 2019;34:68-84

4. Ravidà $A$, Wang IC, Barootchi S, et al. Meta-analysis of randomized clinical trials comparing clinical and patient-reported outcomes between extra-short ( $\leq 6 \mathrm{~mm}$ ) and longer $(\geq 10 \mathrm{~mm}$ ) implants. J Clin Periodontol 2019;46:118-142.

5. Fueki K, Kimoto K, Ogawa T, Garrett NR. Effect of implant-supported or retained dentures on masticatory performance: A systematic review. J Prosthet Dent 2007;98:470-477.

6. Carlsson GE, Lindquist LW. Ten-year longitudinal study of masticatory function in edentulous patients treated with fixed complete dentures on osseointegrated implants. Int J Prosthodont 1994;7:448-453.

7. Harris D, Höfer $S, O^{\prime}$ Boyle CA, et al. A comparison of implantretained mandibular overdentures and conventional dentures on quality of life in edentulous patients: A randomized, prospective, within-subject controlled clinical trial. Clin Oral Implants Res 2013;24:96-103.

8. Zarb GA, Schmitt A. The edentulous predicament. I: A prospective study of the effectiveness of implant-supported fixed prostheses. J Am Dent Assoc 1996;127:59-65.

9. de Souza FI, de Souza Costa A, Dos Santos Pereira R, Dos Santos $\mathrm{PH}$, de Brito RB Jr, Rocha EP. Assessment of satisfaction level of edentulous patients rehabilitated with implant-supported prostheses. Int J Oral Maxillofac Implants 2016;31:884-890.

10. Fischer K, Stenberg T. Prospective 10-year cohort study based on a randomized, controlled trial (RCT) on implant-supported full-arch maxillary prostheses. Part II: Prosthetic outcomes and maintenance. Clin Implant Dent Relat Res 2013;15:498-508.

11. Ravidá A, Barootchi S, Tattan MA, Saleh MHA, Gargallo-Albiol J, Wang HL. Clinical outcomes and cost effectiveness of computerguided versus conventional implant-retained hybrid prostheses: A long-term retrospective analysis of treatment protocols. J Periodontol 2018;89:1015-1024.

12. Bidra AS, Rungruanganunt $P$, Gauthier M. Clinical outcomes of full arch fixed implant-supported zirconia prostheses: A systematic review. Eur J Oral Implantol 2017;10(suppl 1):35-45

13. Bozini T, Petridis H, Garefis K, Garefis P. A meta-analysis of prosthodontic complication rates of implant-supported fixed dental prostheses in edentulous patients after an observation period of at least 5 years. Int J Oral Maxillofac Implants 2011;26:304-318.

14. Purcell BA, McGlumphy EA, Holloway JA, Beck FM. Prosthetic complications in mandibular metal-resin implant-fixed complete dental prostheses: A 5- to 9-year analysis. Int J Oral Maxillofac Implants 2008;23:847-857.

15. Priest G, Smith J, Wilson MG. Implant survival and prosthetic complications of mandibular metal-acrylic resin implant complete fixed dental prostheses. J Prosthet Dent 2014;111:466-475.

16. Ventura J, Jiménez-Castellanos E, Romero J, Enrile F. Tooth fractures in fixed full-arch implant-supported acrylic resin prostheses: A retrospective clinical study. Int J Prosthodont 2016;29:161-165.
17. Ozkurt Z, Kazazoğlu E. Clinical success of zirconia in dental applications. J Prosthodont 2010;19:64-68.

18. Fabbri G, Sorrentino R, Brennan M, Cerutti A. A novel approach to implant screw-retained restorations: Adhesive combination between zirconia frameworks and monolithic lithium disilicate. Int J Esthet Dent 2014;9:490-505.

19. Pozzi A, Holst S, Fabbri G, Tallarico M. Clinical reliability of CAD/ CAM cross-arch zirconia bridges on immediately loaded implants placed with computer-assisted/template-guided surgery: A retrospective study with a follow-up between 3 and 5 years. Clin Implant Dent Relat Res 2015;17(suppl 1):e86-e96.

20. Limmer B, Sanders AE, Reside G, Cooper LF. Complications and patient-centered outcomes with an implant-supported monolithic zirconia fixed dental prosthesis: 1 year results. J Prosthodont 2014;23:267-275.

21. Jemt T, Bäck T, Petersson A. Precision of CNC-milled titanium frameworks for implant treatment in the edentulous jaw. Int Prosthodont 1999;12:209-215.

22. Drago CJ, del Castillo RA. Treatment of edentulous and partially edentulous patients with CAD/CAM frameworks: A pilot case study. Pract Proced Aesthet Dent 2006;18:665-671; quiz 672.

23. Gargallo-Albiol J, Barootchi S, Salomó-Coll O, Wang HL. Advantages and disadvantages of implant navigation surgery. A systematic review. Ann Anat 2019;225:1-10.

24. Denry I, Kelly JR. Emerging ceramic-based materials for dentistry. J Dent Res 2014;93:1235-1242.

25. Papaspyridakos P, Lal K. Computer-assisted design/computer-assisted manufacturing zirconia implant fixed complete prostheses: Clinical results and technical complications up to 4 years of function. Clin Oral Implants Res 2013;24:659-665.

26. Armitage GC. Periodontal diagnoses and classification of periodontal diseases. Periodontol 2000 2004;34:9-21.

27. Pihlstrom BL, Michalowicz BS, Johnson NW. Periodontal diseases Lancet 2005;366:1809-1820.

28. Tonetti M, Palmer R; Working Group 2 of the VIII European Workshop on Periodontology. Clinical research in implant dentistry: Study design, reporting and outcome measurements: Consensus report of Working Group 2 of the VIII European Workshop on Periodontology. J Clin Periodontol 2012;39(suppl 12):73-80.

29. Chrcanovic BR, Albrektsson T, Wennerberg A. Reasons for failures of oral implants. J Oral Rehabil 2014;41:443-476.

30. Ravidà A, Tattan M, Askar H, Barootchi S, Tavelli L, Wang HL. Comparison of three different types of implant-supported fixed partial implant prostheses: A long-term retrospective study of clinical outcomes and cost-effectiveness. Clin Oral Implants Res 2019;30:295-305.

31. Esquivel-Upshaw JF, Anusavice KJ, Young H, Jones J, Gibbs C. Clinical performance of a lithia disilicate-based core ceramic for three-unit posterior FPDs. Int J Prosthodont 2004;17:469-475.

32. Olsson KG, Fürst B, Andersson B, Carlsson GE. A long-term retrospective and clinical follow-up study of In-Ceram Alumina FPDs. Int J Prosthodont 2003;16:150-156.

33. Sagirkaya E, Arikan S, Sadik B, Kara C, Karasoy D, Cehreli M. A randomized, prospective, open-ended clinical trial of zirconia fixed partial dentures on teeth and implants: Interim results. Int J Prosthodont 2012;25:221-231.

34. Vult von Steyern $P$, Jönsson O, Nilner K. Five-year evaluation of posterior all-ceramic three-unit (In-Ceram) FPDs. Int J Prosthodont 2001;14:379-384.

35. Cho Y, Raigrodski AJ. The rehabilitation of an edentulous mandible with a CAD/CAM zirconia framework and heat-pressed lithium disilicate ceramic crowns: A clinical report. J Prosthet Dent 2014;111:443-447.

36. Papaspyridakos P, Chen CJ, Chuang SK, Weber HP, Gallucci GO. A systematic review of biologic and technical complications with fixed implant rehabilitations for edentulous patients. Int J Oral Maxillofac Implants 2012;27:102-110.

37. Papaspyridakos P, Barizan Bordin T, Kim YJ, et al. Implant survival rates and biologic complications with implant-supported fixed complete dental prostheses: A retrospective study with up to 12 year follow-up. Clin Oral Implants Res 2018;29:881-893. 
38. Worni A, Kolgeci L, Rentsch-Kollar A, Katsoulis J, Mericske-Stern R. Zirconia-based screw-retained prostheses supported by implants: A retrospective study on technical complications and failures. Clin Implant Dent Relat Res 2015;17:1073-1081.

39. Larsson C, Vult von Steyern P, Nilner K. A prospective study of implant-supported full-arch yttria-stabilized tetragonal zirconia polycrystal mandibular fixed dental prostheses: Three-year results. Int J Prosthodont 2010;23:364-369.

40. Göthberg C, Bergendal T, Magnusson T. Complications after treatment with implant-supported fixed prostheses: A retrospective study. Int J Prosthodont 2003;16:201-207.

41. Naert I, Quirynen M, van Steenberghe D, Darius P. A study of 589 consecutive implants supporting complete fixed prostheses. Part II: Prosthetic aspects. J Prosthet Dent 1992;68:949-956.

42. Moberg LE, Köndell PA, Sagulin GB, Bolin A, Heimdahl A, Gynther GW. Brånemark System and ITI Dental Implant System for treatment of mandibular edentulism. A comparative randomized study: 3-year follow-up. Clin Oral Implants Res 2001;12:450-461.

43. Zarb GA, Schmitt A. The longitudinal clinical effectiveness of osseointegrated dental implants: The Toronto study. Part III: Problems and complications encountered. J Prosthet Dent 1990;64:185-194.

44. Box VH, Sukotjo C, Knoernschild KL, Campbell SD, Afshari FS. Patient-reported and clinical outcomes of implant-supported fixed complete dental prostheses: A comparison of metal-acrylic, milled zirconia, and retrievable crown prostheses. J Oral Implantol 2018;44:51-61.
45. Maló P, de Araújo Nobre M, Borges J, Almeida R. Retrievable metal ceramic implant-supported fixed prostheses with milled titanium frameworks and all-ceramic crowns: Retrospective clinical study with up to 10 years of follow-up. J Prosthodont 2012;21:256-264.

46. Gonzalez J, Triplett RG. Complications and clinical considerations of the implant-retained zirconia complete-arch prosthesis with various opposing dentitions. Int J Oral Maxillofac Implants 2017;32:864-869.

47. Ravidà A, Barootchi S, Alkanderi A, Tavelli L, Suárez-López Del Amo F. The effect of crown-to-implant ratio on the clinical outcomes of dental implants: A systematic review. Int J Oral Maxillofac Implants 2019;34:1121-1131.

48. Karoussis IK, Salvi GE, Heitz-Mayfield LJ, Brägger U, Hämmerle $\mathrm{CH}$, Lang NP. Long-term implant prognosis in patients with and without a history of chronic periodontitis: A 10-year prospective cohort study of the ITI Dental Implant System. Clin Oral Implants Res 2003;14:329-339.

49. Kolgeci L, Mericske E, Worni A, Walker P, Katsoulis J, Mericske-Stern R. Technical complications and failures of zirconia-based prostheses supported by implants followed up to 7 years: A case series. Int J Prosthodont 2014;27:544-552.

50. Maló P, de Araujo Nobre M, Rangert B. Implants placed in immediate function in periodontally compromised sites: A five-year retrospective and one-year prospective study. J Prosthet Dent 2007;97(6 suppl):s86-s95. 
Appendix 1 STROBE Checklist

\begin{tabular}{|c|c|c|}
\hline & Item No & Recommendation \\
\hline Title and abstract & 1 & $\begin{array}{l}\text { (a) Indicate the study's design with a commonly used term in the title or the abstract - page } 395 \\
\text { (b) Provide in the abstract an informative and balanced summary of what was done and what was found } \\
\text { - page } 395\end{array}$ \\
\hline \multicolumn{3}{|l|}{ Introduction } \\
\hline Background/rationale & 2 & $\begin{array}{l}\text { Explain the scientific background and rationale for the investigation being reported } \\
\text { - pages 395-396 }\end{array}$ \\
\hline Objectives & 3 & State specific objectives, including any prespecified hypotheses - page 396 \\
\hline \multicolumn{3}{|l|}{ Methods } \\
\hline Study design & 4 & Present key elements of study design early in the paper - page 396 \\
\hline Setting & 5 & $\begin{array}{l}\text { Describe the setting, locations, and relevant dates, including periods of recruitment, exposure, follow-up, } \\
\text { and data collection - pages 396-397 }\end{array}$ \\
\hline Participants & 6 & (a) Give the eligibility criteria, and the sources and methods of selection of participants - pages 396-398 \\
\hline Variables & 7 & $\begin{array}{l}\text { Clearly define all outcomes, exposures, predictors, potential confounders, and effect modifiers. Give } \\
\text { diagnostic criteria, if applicable - pages 397-398 }\end{array}$ \\
\hline $\begin{array}{l}\text { Data sources/ } \\
\text { measurement }\end{array}$ & 8* & $\begin{array}{l}\text { For each variable of interest, give sources of data and details of methods of assessment (measurement). } \\
\text { Describe comparability of assessment methods if there is more than one group - for both groups all } \\
\text { complication assessments, and cost analyses are described in pages 397-398 }\end{array}$ \\
\hline Bias & 9 & $\begin{array}{l}\text { Describe any efforts to address potential sources of bias - A thorough search of all implant treatment } \\
\text { cases was carried out and reviewed against the criteria by two reviewers (page 396) }\end{array}$ \\
\hline Study size & 10 & Explain how the study size was arrived at - page 396 \\
\hline Quantitative variables & 11 & $\begin{array}{l}\text { Explain how quantitative variables were handled in the analyses. If applicable, describe which groupings } \\
\text { were chosen and why - pages 397-398 }\end{array}$ \\
\hline Statistical methods & 12 & $\begin{array}{l}\text { (a) Describe all statistical methods, including those used to control for confounding - page } 398 \\
\text { (b) Describe any methods used to examine subgroups and interactions - page } 398 \\
\text { (c) Explain how missing data were addressed - no missing data were encountered } \\
\text { (d) If applicable, describe analytical methods taking account of sampling strategy - pages 397-398 } \\
\text { (e) Describe any sensitivity analyses - page } 398\end{array}$ \\
\hline
\end{tabular}

\section{Results}

Participants $\quad 13^{*} \quad$ (a) Report numbers of individuals at each stage of study-eg, numbers potentially eligible, examined for eligibility, confirmed eligible, included in the study, completing follow-up, and analyzed - page 398 (b) Give reasons for non-participation at each stage - page 398

(c) Consider use of a flow diagram - due to the numerous figures, the inclusion of patients was descriptively reported

Descriptive data $\quad 14^{*} \quad$ (a) Give characteristics of study participants (eg, demographic, clinical, social) and information on exposures and potential confounders - page 398 and Table 1

(b) Indicate number of participants, with missing data for each variable of interest -page 398 and Table 1 Outcome data 15* Report numbers of outcome events or summary measures - pages 399-401

Main results $\quad 16 \quad$ (a) Give unadjusted estimates and, if applicable, confounder-adjusted estimates and their precision (eg, $95 \%$ confidence interval). Make clear which confounders were adjusted for and why they were included pages 399-401

(b) Report category boundaries when continuous variables were categorized - pages 399-400

(c) If relevant, consider translating estimates of relative risk into absolute risk for a meaningful time period - not applicable

\begin{tabular}{|c|c|c|}
\hline Other analyses & 17 & $\begin{array}{l}\text { Report other analyses done-eg, analyses of subgroups and interactions, and sensitivity analyses - } \\
\text { pages 399-401 }\end{array}$ \\
\hline \multicolumn{3}{|l|}{ Discussion } \\
\hline Key results & 18 & Summarize key results with reference to study objectives - pages $401-403$ \\
\hline Limitations & 19 & $\begin{array}{l}\text { Discuss limitations of the study, taking into account sources of potential bias or imprecision. Discuss } \\
\text { both direction and magnitude of any potential bias - page } 403\end{array}$ \\
\hline Interpretation & 20 & $\begin{array}{l}\text { Give a cautious overall interpretation of results considering objectives, limitations, multiplicity of } \\
\text { analyses, results from similar studies, and other relevant evidence - page } 403\end{array}$ \\
\hline Generalizability & 21 & Discuss the generalizability (external validity) of the study results - page 403 \\
\hline \multicolumn{3}{|c|}{ Other information } \\
\hline Funding & 22 & $\begin{array}{l}\text { Give the source of funding and the role of the funders for the present study and, if applicable, for the } \\
\text { original study on which the present article is based - page } 404\end{array}$ \\
\hline
\end{tabular}

*Give information separately for exposed and unexposed groups.

Note: An Explanation and Elaboration article discusses each checklist item and gives methodological background and published examples of transparent reporting. The STROBE checklist is best used in conjunction with this article (freely available on the Web sites of PLoS Medicine at http://www.plosmedicine.org/, Annals of Internal Medicine at http://www.annals.org/, and Epidemiology at http://www.epidem.com/). Information on the STROBE Initiative is available at www.strobe-statement.org. 


\section{APPENDIX 2}

\section{Surgical Procedures}

In case of a computer-guided surgery, digital 3D diagnostic and treatment planning were performed by the company software (Nobel Biocare), which defined the implant position and size by combining the future 3D teeth setup and the patient's anatomy. Treatment planning involved cone beam computed tomography (CBCT) (3DX Accuitomo FPD; J Morita Mfg) or CT scans of both the patient and the prosthetic-driven radiographic guide following the double-scan protocol: a first scan of the patient wearing the radiographic guide prepared after the diagnostic tooth set-up, and a second scan only of the template. Next, both scans were superimposed for optimal implant positioning. The software planning data were then sent to the manufacturer (Nobel Biocare), where a surgical template with hollow metallic sleeves was designed and produced to guide the implants accordingly. When immediate loading was necessary, full acrylic resin screwretained provisional prostheses were prefabricated based on the surgical guide, and the model obtained from the surgical templates was placed intraorally in the proper position and fixed with anchorage pins. After correct placement and stabilization of the surgical template, flapless implant surgery and fully guided implant placement were performed following the drilling protocol.

In cases of non-computer-guided implant placement, the rehabilitation was first planned on panoramic radiographs or 3D (CBCT or CT) diagnostic imaging. Consequent$l y$, surgical guides were constructed from the diagnostic tooth set-up and cast model analysis using a light-polymerized composite material, where drill blanks placed in the prosthodontically driven implant position were set to assist the free-hand surgery. After a full-thickness flap reflection for sufficient exposure and access to bone (and a vertical incision if necessitated), the conventional drilling sequence proceeded according to manufacturer instruction. A variety of implant systems (NobelSpeedy groovy, NobelActive, and NobelReplace Tapered Groovy implant, Nobel Biocare; Zimmer TSV, Zimmer; Brånemark Mark III and IV, Biohorizons) were utilized in this group. Guided bone regeneration (GBR) was performed simultaneously, when necessary, using allograft particulate bone (Puros Zimmer) and an absorbable collagen membrane (Bio-Gide, Geistlich Pharma) to repair bone defects and augment horizontal bone volume. Some of the patients were restored with a fixed provisional, immediately loaded prosthesis, while others went for early or delayed loading depending on the primary stability.

\section{Metal-Acrylic Prosthesis Group}

After healing, all implants were connected with resin (Autopolymerizing acrylic resin, ALIKE; GC America, ALSIP), and impressions were taken using the implant level-open-tray technique. A verification jig was used to determine the accuracy of the impression and to record the initial jaw relationships. The cast was mounted on a non-arcon semiadjustable articulator, using an arbitrary facebow and interocclusal records. Castable abutments were used, and the wax-up for framework fabrication was done. After casting, the fitting of the framework was carried out using a disclosing media (Kerr's Disclosing Wax, Kerr; and Occlude, Pascal) in order to seat the framework passively. Resin denture teeth were waxed to the metal framework, and a final wax try-in was carried out to check the esthetic and phonetic aspects along with maxilla-mandibular relationships. Prior to delivery, the prosthesis was polished after the flasking procedure, and the occlusal contacts were refined through a clinical remount (Appendix 3).

\section{Zirconia Prosthesis Group}

After healing, custom-made abutments were placed, and a monolithic zirconia prosthesis was virtually planned using the Procera Implant Bridge system (Nobel Biocare). The prosthesis was designed to load single ceramic crowns (IPS e.max ZirPress, Ivoclar Vivadent) to establish a highly esthetic prosthesis (with minimal ceramic thickness of $1 \mathrm{~mm}$ in the anterior and $1.5 \mathrm{~mm}$ in the posterior regions). A Nobel Procera Zirconia Implant framework was milled by the manufacturer. To mimic the missing gingival tissues, light cured resin material was applied according to the position of the crowns (Appendix 4a). The prosthesis was screwed to the implants, and full ceramic crowns were designed to fit on their relative abutments on the Procera Implant Bridge. All crowns were cemented using a self-adhesive resin cement (Ivoclar Vivadent) (Appendix 4b), and occlusal adjustments were made to achieve a harmonious occlusion.

\section{Cost Analysis}

The main goal was obtaining a more comprehensive perception of cost-effectiveness and to compare both approaches. The average cost for all clinical procedures was determined throughout the follow-up period, which was then used to standardize the fees among both groups. The costs were categorized into the following:

- Initial cost: That included all fees for implant placement and prosthetic rehabilitation. Within the initial cost, every treatment fee, such as preliminary consultation appointments, use of any diagnostic aids, laboratory fees, preparations, and the entire cost of surgery were included.

- Cost for complication management: The expenses associated with complications related to implant and prosthesis management. Included any fee related to follow-up maintenance, as well as management of any biologic or prosthetic complication pertaining to any of the components.

- Total cost: The sum of initial cost and cost for complication management 
The cost of all treatments associated with initial placement and management procedures were predetermined based on an average of their individual costs every year since 1990, at the University of Michigan, School of Dentistry to formulate a price list. Next, all the procedures pertaining to each patient file were scanned and recorded by one study investigator (H.A.). Wherever doubt arose, an expert in the matter (H.L.W.) was referred to. With these records, the cost of performed treatments and managements for each patient was computed into the aforementioned categories. Thus, whether or not a patient had actually paid for the provided treatments, the actual cost was presumed within the particular patient's cost of treatment.

The average cost of each procedure was calculated as follows:

$$
\text { Cost }=\frac{\text { Cost }_{1}+\text { Cost }_{2}+\operatorname{Cost}_{3}+\text { Cost }_{4}+\ldots+\text { Cost }_{n}}{n}
$$

Cost $_{\mathrm{x}}=$ Total Procedure Expenditure at a Given Year ( year $_{x}$ )

$\mathrm{n}=$ Total number of Cost $_{\mathrm{x}}$ events for a prosthesis

\section{Table A1 Participant Data and Descriptive Analysis of Technical Complications (Metal-Acrylic Fixed} Implant Prosthesis)

\begin{tabular}{|c|c|c|c|c|c|c|c|c|c|}
\hline \multicolumn{3}{|c|}{ Participants } & \multicolumn{7}{|c|}{ Implants } \\
\hline $\mathbf{N}$ & Sex & Age (y) & $\mathbf{N}$ & $\begin{array}{c}\text { Immediate } \\
\text { vs } \\
\text { delayed }\end{array}$ & Arch & Opposing & $\begin{array}{l}\text { Follow-up } \\
\text { duration } \\
\text { (month) }\end{array}$ & $\begin{array}{l}\text { Implant } \\
\text { failure }\end{array}$ & $\begin{array}{c}\text { Screw } \\
\text { loosening }\end{array}$ \\
\hline 1 & $\mathrm{~F}$ & 63 & 8 & Delayed & Maxilla & Teeth/Crowns & 146 & & \\
\hline 2 & $\mathrm{~F}$ & 58 & 6 & Delayed & Maxilla & Teeth/Implants & 129 & & \\
\hline 3 & M & 61 & 5 & Delayed & Mandible & Denture & 156 & & \\
\hline 4 & $\mathrm{~F}$ & 53 & 5 & Delayed & Mandible & MA hybrid & 175 & & \\
\hline 5 & $\mathrm{~F}$ & 58 & 6 & Delayed & Maxilla & RPD & 82 & & \\
\hline 6 & $\mathrm{~F}$ & 56 & 6 & Immediate & Mandible & Teeth/Implants & 137 & 6 & \\
\hline 7 & $\mathrm{~F}$ & 61 & 5 & Delayed & Mandible & MA hybrid & 174 & & \\
\hline 8 & $\mathrm{~F}$ & 51 & 5 & Delayed & Maxilla & MA hybrid & 86 & 5 & \\
\hline 9 & $\mathrm{~F}$ & 51 & 5 & Delayed & Mandible & MA hybrid & 86 & 5 & \\
\hline 10 & $\mathrm{~F}$ & 52 & 8 & Delayed & Maxilla & Teeth/Implants & 95 & & \\
\hline 11 & M & 80 & 5 & Delayed & Mandible & MA hybrid & 93 & 5 & 1 \\
\hline 12 & $\mathrm{~F}$ & 62 & 6 & Immediate & Mandible & Denture & 154 & & \\
\hline 13 & $\mathrm{~F}$ & 71 & 6 & Delayed & Maxilla & MA hybrid & 66 & & \\
\hline 14 & $\mathrm{~F}$ & 44 & 5 & Delayed & Mandible & Denture & 284 & & 2 \\
\hline 15 & M & 22 & 7 & Delayed & Maxilla & MA hybrid & 125 & & \\
\hline 16 & M & 22 & 6 & Delayed & Mandible & MA hybrid & 126 & & \\
\hline 17 & M & 43 & 5 & Delayed & Mandible & MA hybrid & 242 & & \\
\hline 18 & M & 45 & 8 & Delayed & Maxilla & MA hybrid & 174 & 6 & \\
\hline 19 & M & 49 & 5 & Delayed & Mandible & MA hybrid & 116 & & \\
\hline 20 & M & 49 & 6 & Delayed & Maxilla & MA hybrid & 174 & & \\
\hline 21 & M & 59 & 6 & Delayed & Maxilla & Teeth/Crowns & 73 & & \\
\hline 22 & M & 79 & 5 & Delayed & Mandible & Denture & 60 & & \\
\hline 23 & M & 78 & 5 & Delayed & Mandible & Crowns & 119 & & \\
\hline 24 & M & 48 & 5 & Delayed & Mandible & Denture & 92 & & \\
\hline 25 & M & 81 & 5 & Delayed & Mandible & Imp Over & 92 & & \\
\hline 26 & $\mathrm{~F}$ & 63 & 8 & Delayed & Maxilla & Teeth/Crowns & 80 & & \\
\hline 27 & M & 64 & 8 & Immediate & Maxilla & MA hybrid & 92 & & \\
\hline 28 & M & 60 & 6 & Immediate & Mandible & MA hybrid & 136 & & \\
\hline 29 & M & 69 & 6 & Delayed & Maxilla & MA hybrid & 85 & & \\
\hline 30 & M & 71 & 5 & Delayed & Mandible & MA hybrid & 67 & 1 & \\
\hline 31 & $\mathrm{~F}$ & 78 & 6 & Delayed & Maxilla & Teeth/Crowns & 98 & 1 & \\
\hline 32 & $\mathrm{~F}$ & 46 & 5 & Delayed & Mandible & Teeth & 124 & & 5 \\
\hline
\end{tabular}

MA hybrids = metal-acrylic hybrid prosthesis; RPD = removable partial denture; Imp Over = implant overdenture. 
Technical complications

\begin{tabular}{|c|c|c|c|c|c|c|}
\hline $\begin{array}{l}\text { Abutment } \\
\text { fracture }\end{array}$ & $\begin{array}{l}\text { Incidence of single tooth } \\
\text { fracture/dislodgment } \\
\text { (chairside repair) }\end{array}$ & $\begin{array}{l}\text { Incidence of multiple } \\
\text { teeth fracture and/or } \\
\text { labwork required }\end{array}$ & $\begin{array}{c}\text { Acrylic } \\
\text { fracture }\end{array}$ & $\begin{array}{l}\text { Framework } \\
\text { fracture }\end{array}$ & $\begin{array}{l}\text { Prosthesis } \\
\text { replacement }\end{array}$ & $\begin{array}{l}\text { Catastrophic } \\
\text { failure }\end{array}$ \\
\hline & 6 & & 2 & 1 & 1 & \\
\hline & 7 & 2 & & & & \\
\hline & & & 3 & & & \\
\hline & & & & & 1 & \\
\hline & & & & & 1 & \\
\hline & 4 & 2 & & 1 & 1 & \\
\hline & 2 & & & & & \\
\hline & 2 & & & & 1 & 1 \\
\hline & & & & & 2 & \\
\hline & 2 & & & & & \\
\hline 2 & & & & & 1 & \\
\hline & 1 & 1 & 2 & & & \\
\hline & 2 & & & & & \\
\hline & 6 & 8 & & 3 & 2 & \\
\hline & 5 & 1 & 1 & & 2 & \\
\hline & 8 & 2 & & & 2 & \\
\hline & & & & & 1 & \\
\hline & & & 2 & & 1 & \\
\hline & 4 & 1 & & & & \\
\hline & 5 & 1 & 2 & & & \\
\hline & 4 & 4 & & & & \\
\hline 2 & & 2 & 1 & & 1 & \\
\hline & 5 & 1 & 2 & & 1 & \\
\hline & & & & & 1 & 1 \\
\hline
\end{tabular}




\begin{tabular}{|c|c|c|c|c|c|c|c|c|c|}
\hline \multicolumn{3}{|c|}{ Participants } & \multicolumn{7}{|c|}{ Implants } \\
\hline $\mathbf{N}$ & Sex & Age (y) & $\mathbf{N}$ & $\begin{array}{c}\text { Immediate } \\
\text { vs } \\
\text { delayed }\end{array}$ & Arch & Opposing & $\begin{array}{l}\text { Follow-up } \\
\text { duration } \\
\text { (month) }\end{array}$ & $\begin{array}{l}\text { Implant } \\
\text { failure }\end{array}$ & $\begin{array}{c}\text { Screw } \\
\text { loosening }\end{array}$ \\
\hline 33 & $\mathrm{~F}$ & 60 & 5 & Delayed & Mandible & Denture & 120 & & 1 \\
\hline 34 & M & 65 & 6 & Delayed & Maxilla & Teeth/Crowns & 107 & 1 & \\
\hline 35 & $\mathrm{~F}$ & 62 & 6 & Delayed & Maxilla & Teeth/Crowns & 133 & & \\
\hline 36 & M & 59 & 6 & Immediate & Mandible & MA hybrid & 126 & & \\
\hline 37 & M & 60 & 6 & Immediate & Maxilla & MA hybrid & 120 & & \\
\hline 38 & $F$ & 51 & 6 & Delayed & Maxilla & MA hybrid & 74 & & \\
\hline 39 & M & 57 & 5 & Delayed & Mandible & MA hybrid & 95 & & \\
\hline 40 & M & 57 & 6 & Delayed & Maxilla & MA hybrid & 91 & 1 & \\
\hline 41 & $\mathrm{~F}$ & 62 & 6 & Delayed & Maxilla & Crowns & 85 & & \\
\hline 42 & M & 83 & 5 & Delayed & Maxilla & Teeth/Implants & 60 & & \\
\hline \multirow[t]{2}{*}{43} & $\mathrm{~F}$ & 65 & 7 & Delayed & Maxilla & MA hybrid & 125 & 1 & \\
\hline & $\begin{array}{l}20 \mathrm{~F} \\
23 \mathrm{M}\end{array}$ & 58.7 & 252 & & $\begin{array}{l}22 \text { Maxilla } \\
21 \text { Mandible }\end{array}$ & & $\begin{array}{r}118 \pm \\
45.8\end{array}$ & & 9 \\
\hline
\end{tabular}

MA hybrids = metal-acrylic hybrid prosthesis; RPD = removable partial denture; Imp Over = implant overdenture.

\section{Table A2 Participant Data and Descriptive Analysis of Technical Complications (Zirconia Fixed Implant Prosthesis)}

\begin{tabular}{|c|c|c|c|c|c|c|c|c|}
\hline \multicolumn{3}{|c|}{ Participants } & \multicolumn{6}{|c|}{ Implants } \\
\hline $\mathbf{N}$ & Sex & Age (y) & $\mathbf{N}$ & $\begin{array}{c}\text { Immediate } \\
\text { vs } \\
\text { delayed }\end{array}$ & Arch & Opposing & $\begin{array}{c}\text { Follow-up } \\
\text { duration (mo) }\end{array}$ & $\begin{array}{l}\text { Implant } \\
\text { failure }\end{array}$ \\
\hline 1 & $\mathrm{~F}$ & 53 & 7 & Delayed & Maxilla & Teeth/Implants & 92 & \\
\hline 2 & M & 48 & 6 & Delayed & Maxilla & IZFP & 67 & \\
\hline 3 & M & 48 & 5 & Delayed & Mandible & IZFP & 69 & 1 \\
\hline 4 & $M$ & 33 & 8 & Delayed & Maxilla & IZFP & 60 & \\
\hline 5 & $\mathrm{M}$ & 33 & 6 & Delayed & Mandible & IZFP & 60 & \\
\hline 6 & $\mathrm{M}$ & 81 & 6 & Delayed & Maxilla & Teeth & 68 & \\
\hline 7 & M & 74 & 6 & Delayed & Maxilla & IZFP & 58 & \\
\hline 8 & $M$ & 74 & 5 & Delayed & Mandible & IZFP & 58 & 1 \\
\hline 9 & $\mathrm{~F}$ & 58 & 7 & Delayed & Maxilla & Crowns/Implants & 97 & 1 \\
\hline 10 & $\mathrm{~F}$ & 54 & 8 & Delayed & Maxilla & Teeth/Crowns & 123 & \\
\hline 11 & $\mathrm{~F}$ & 63 & 8 & Delayed & Maxilla & IZFP & 104 & \\
\hline 12 & $\mathrm{~F}$ & 63 & 6 & Delayed & Mandible & IZFP & 104 & \\
\hline 13 & M & 80 & 6 & Delayed & Maxilla & IZFP & 132 & \\
\hline 14 & $\mathrm{~F}$ & 50 & 5 & Delayed & Mandible & IZFP & 101 & 4 \\
\hline 15 & $\mathrm{~F}$ & 65 & 5 & Delayed & Mandible & IZFP & 123 & \\
\hline 16 & M & 55 & 6 & Delayed & Maxilla & IZFP & 99 & \\
\hline 17 & M & 55 & 5 & Delayed & Mandible & IZFP & 98 & \\
\hline 18 & M & 64 & 8 & Delayed & Maxilla & IZFP & 60 & \\
\hline 19 & M & 50 & 6 & Delayed & Maxilla & IZFP & 80 & \\
\hline 20 & M & 50 & 5 & Delayed & Mandible & IZFP & 79 & \\
\hline 21 & M & 71 & 8 & Delayed & Maxilla & IZFP & 132 & \\
\hline 22 & M & 71 & 7 & Delayed & Mandible & IZFP & 119 & 7 \\
\hline 23 & $\mathrm{~F}$ & 78 & 5 & Delayed & Mandible & IZFP & 116 & \\
\hline 24 & $\mathrm{~F}$ & 69 & 7 & Delayed & Maxilla & IZFP & 63 & \\
\hline 25 & $\mathrm{~F}$ & 69 & 8 & Delayed & Mandible & IZFP & 63 & \\
\hline 26 & $M$ & 56 & 6 & Delayed & Maxilla & IZFP & 105 & \\
\hline
\end{tabular}

IZFP = implant-supported zirconia fixed prosthesis. 
Technical complications

\begin{tabular}{|c|c|c|c|c|c|c|}
\hline $\begin{array}{l}\text { Abutment } \\
\text { fracture }\end{array}$ & $\begin{array}{l}\text { Incidence of single tooth } \\
\text { fracture/dislodgment } \\
\text { (chairside repair) }\end{array}$ & $\begin{array}{l}\text { Incidence of multiple } \\
\text { teeth fracture and/or } \\
\text { labwork required }\end{array}$ & $\begin{array}{l}\text { Acrylic } \\
\text { fracture }\end{array}$ & $\begin{array}{l}\text { Framework } \\
\text { fracture }\end{array}$ & $\begin{array}{l}\text { Prosthesis } \\
\text { replacement }\end{array}$ & $\begin{array}{l}\text { Catastrophic } \\
\text { failure }\end{array}$ \\
\hline & 3 & 4 & & & & \\
\hline & 2 & & & & & \\
\hline & & 1 & & & 1 & \\
\hline & 3 & & & & 1 & \\
\hline & 5 & 1 & & & & \\
\hline & 8 & 2 & & & & \\
\hline & 2 & 3 & 1 & & 1 & \\
\hline 1 & 8 & 5 & 1 & & 1 & \\
\hline 5 & 94 & 41 & 17 & 5 & 23 & 2 \\
\hline
\end{tabular}

Technical complications

\begin{tabular}{|c|c|c|c|c|c|c|}
\hline $\begin{array}{c}\text { Screw } \\
\text { loosening }\end{array}$ & $\begin{array}{c}\text { Re- } \\
\text { cementation }\end{array}$ & $\begin{array}{l}\text { Incidence of single tooth } \\
\text { chipping/fracture } \\
\text { chairside repair) }\end{array}$ & $\begin{array}{l}\text { Incidence of multiple } \\
\text { teeth fracture and/or } \\
\text { labwork required }\end{array}$ & $\begin{array}{l}\text { Zirconia } \\
\text { bar } \\
\text { fracture }\end{array}$ & $\begin{array}{l}\text { Prosthesis } \\
\text { replacement }\end{array}$ & $\begin{array}{c}\text { Catastrophic } \\
\text { failure }\end{array}$ \\
\hline
\end{tabular}

1

1

1

6

1

1

1

1

4

2

5

1

$\begin{array}{ll}1 & 1 \\ 1 & 7\end{array}$

1

1

1

1

1

1

(c) 2020 BY QUINTESSENCE PUBLISHING CO, INC. PRINTING OF THIS DOCUMENT IS RESTRICTED TO PERSONAL USE ONLY. NO PART MAY BE REPRODUCED OR TRANSMITTED IN ANY FORM WITHOUT WRITTEN PERMISSION FROM THE PUBLISHER. 


\begin{tabular}{|c|c|c|c|c|c|c|c|c|}
\hline \multicolumn{3}{|c|}{ Participants } & \multicolumn{6}{|c|}{ Implants } \\
\hline $\mathbf{N}$ & Sex & Age (y) & $\mathbf{N}$ & $\begin{array}{c}\text { Immediate } \\
\text { vs } \\
\text { delayed }\end{array}$ & Arch & Opposing & $\begin{array}{c}\text { Follow-up } \\
\text { duration (mo) }\end{array}$ & $\begin{array}{l}\text { Implant } \\
\text { failure }\end{array}$ \\
\hline 27 & M & 52 & 8 & Delayed & Maxilla & IZFP & 93 & \\
\hline 28 & M & 52 & 7 & Delayed & Mandible & IZFP & 93 & \\
\hline 29 & $\mathrm{~F}$ & 78 & 8 & Delayed & Maxilla & IZFP & 112 & \\
\hline 30 & M & 52 & 6 & Delayed & Maxilla & IZFP & 95 & 5 \\
\hline \multirow[t]{2}{*}{31} & M & 52 & 6 & Delayed & Mandible & IZFP & 95 & \\
\hline & $\begin{array}{l}11 \mathrm{~F} \\
20 \mathrm{M}\end{array}$ & 59.7 & 200 & & $\begin{array}{l}18 \text { Maxilla } \\
13 \text { Mandible }\end{array}$ & & $90.9 \pm 23.49$ & \\
\hline
\end{tabular}

IZFP = implant-supported zirconia fixed prosthesis.

\section{Table A3 Incidence of Complications Per Year for Metal-Acrylic and Zirconia Fixed Implant} Prostheses Throughout The Follow-up

\begin{tabular}{|c|c|c|c|c|c|c|c|c|c|}
\hline \multirow{2}{*}{$\begin{array}{l}\text { Type of } \\
\text { prosthesis }\end{array}$} & \multirow[b]{2}{*}{ Incidence of events } & \multicolumn{7}{|c|}{ Time (mo) } & \multirow[b]{2}{*}{ Total } \\
\hline & & $0-12$ & $12-24$ & $24-36$ & $36-48$ & $48-60$ & $60-120$ & $120+$ & \\
\hline \multirow[t]{10}{*}{ Metal-acrylic } & Screw loosening & & & & & & 5 & 2 & 7 \\
\hline & Abutment fracture & & & 1 & & & 1 & 1 & 3 \\
\hline & $\begin{array}{l}\text { Single tooth fracture/ } \\
\text { dislodgment }\end{array}$ & 11 & 8 & 12 & 14 & 7 & 29 & 12 & 93 \\
\hline & $\begin{array}{l}\text { Multiple teeth fracture/ } \\
\text { dislodgment }\end{array}$ & 1 & 3 & 5 & 2 & 7 & 15 & 5 & 38 \\
\hline & Acrylic fracture & 3 & 3 & 2 & 1 & 2 & 3 & 4 & 18 \\
\hline & Framework fracture & & 2 & & 2 & 3 & 1 & 1 & 9 \\
\hline & Prosthesis replacement & & & 3 & 3 & & 12 & 4 & 22 \\
\hline & Implant failure & 4 & & 2 & & 1 & 11 & & 18 \\
\hline & Catastrophic failure & 1 & & & & & 1 & & 2 \\
\hline & Number of prostheses followed & 46 & 46 & 46 & 46 & 46 & 41 & 20 & \\
\hline \multirow[t]{9}{*}{ Zirconia } & Screw loosening & 2 & & & 1 & 1 & & & 3 \\
\hline & Re-cementation & 2 & 2 & 4 & 3 & & 3 & & 14 \\
\hline & Single tooth ceramic chipping & 5 & 3 & 7 & 3 & 4 & 5 & & 27 \\
\hline & Multiple tooth ceramic chipping & 5 & 3 & 2 & 3 & 2 & & & 15 \\
\hline & Prosthesis replacement & 1 & & & & 1 & 1 & & 3 \\
\hline & Bar fracture & 2 & & & & & 1 & & 3 \\
\hline & Implant loss & 1 & & & & 4 & 1 & & 6 \\
\hline & Catastrophic failure & & & & & & 2 & & 2 \\
\hline & Number of prostheses followed & 31 & 31 & 31 & 29 & 31 & 26 & & \\
\hline
\end{tabular}




\begin{tabular}{ccccccc}
\multicolumn{10}{c}{ Technical complications } \\
\hline Screw & $\begin{array}{c}\text { Re- } \\
\text { loosening }\end{array}$ & $\begin{array}{c}\text { Incidence of single tooth } \\
\text { chipping/fracture } \\
\text { chairside repair) }\end{array}$ & $\begin{array}{c}\text { Incidence of multiple } \\
\text { teeth fracture and/or } \\
\text { labwork required }\end{array}$ & $\begin{array}{c}\text { Zirconia } \\
\text { bar } \\
\text { fracture }\end{array}$ & $\begin{array}{c}\text { Prosthesis } \\
\text { replacement }\end{array}$ & $\begin{array}{c}\text { Catastrophic } \\
\text { failure }\end{array}$
\end{tabular}

12

1

1

4
1

36
3

9
1

1

3

4

2

\section{Table A4 Associated Costs with the Zirconia and the Metal-Acrylic Prostheses}

\begin{tabular}{|c|c|c|c|c|}
\hline & & \multicolumn{2}{|c|}{ Prosthesis group } & \multirow[b]{2}{*}{ Total } \\
\hline & & Resin & Zirconia & \\
\hline \multirow[t]{7}{*}{ Initial cost } & $\mathrm{N}$ & 43 & 31 & 74 \\
\hline & Mean & $12,023.8$ & $20,518.2$ & $15,582.2$ \\
\hline & Standard deviation & $1,480.2$ & $2,173.6$ & $4,583.3$ \\
\hline & Minimum & $9,040.0$ & $16,286.0$ & $9,040.0$ \\
\hline & Maximum & $16,264.0$ & $24,586.0$ & $24,586.0$ \\
\hline & Median & $11,889.0$ & $20,751.0$ & $13,026.0$ \\
\hline & Sum & $517,023.0$ & $636,063.0$ & $1,153,086.0$ \\
\hline \multirow[t]{7}{*}{ Complication cost } & $\mathrm{N}$ & 43 & 31 & 74 \\
\hline & Mean & $2,041.4$ & $2,185.4$ & $2,101.7$ \\
\hline & Standard deviation & $2,841.1$ & $5,846.7$ & $4,324.0$ \\
\hline & Minimum & 0.0 & 0.0 & 0.0 \\
\hline & Maximum & $11,347.0$ & $32,630.0$ & $32,630.0$ \\
\hline & Median & 366.0 & 486.0 & 410.5 \\
\hline & Sum & $87,779.0$ & $67,747.0$ & $155,526.0$ \\
\hline \multirow[t]{7}{*}{ Total cost } & $\mathrm{N}$ & 43 & 31 & 74 \\
\hline & Mean & $14,065.2$ & $22,703.5$ & $17,683.9$ \\
\hline & Standard deviation & $3,126.9$ & $5,963.5$ & $6,217.3$ \\
\hline & Minimum & $9,133.0$ & $17,385.0$ & $9,133.0$ \\
\hline & Maximum & $22,356.0$ & $52,216.0$ & $52,216.0$ \\
\hline & Median & $13,066.0$ & $21,431.0$ & $17,304.5$ \\
\hline & Sum & $604,802.0$ & $703,810.0$ & $1,308,612.0$ \\
\hline
\end{tabular}

All expenses refer to standardized costs in U.S. dollars. 


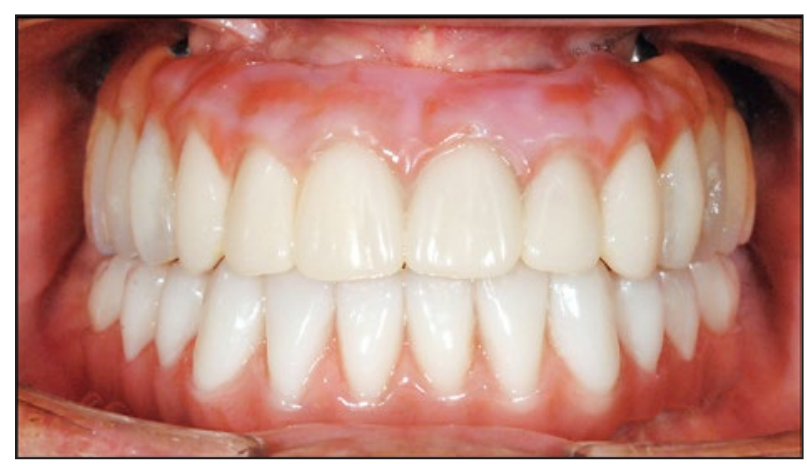

Appendix 3 (Left) Intraoral view of metal-acrylic hybrid prosthesis.

Appendix 4 (Below) (a) Zirconia framework. (b) After cementation of the crowns.
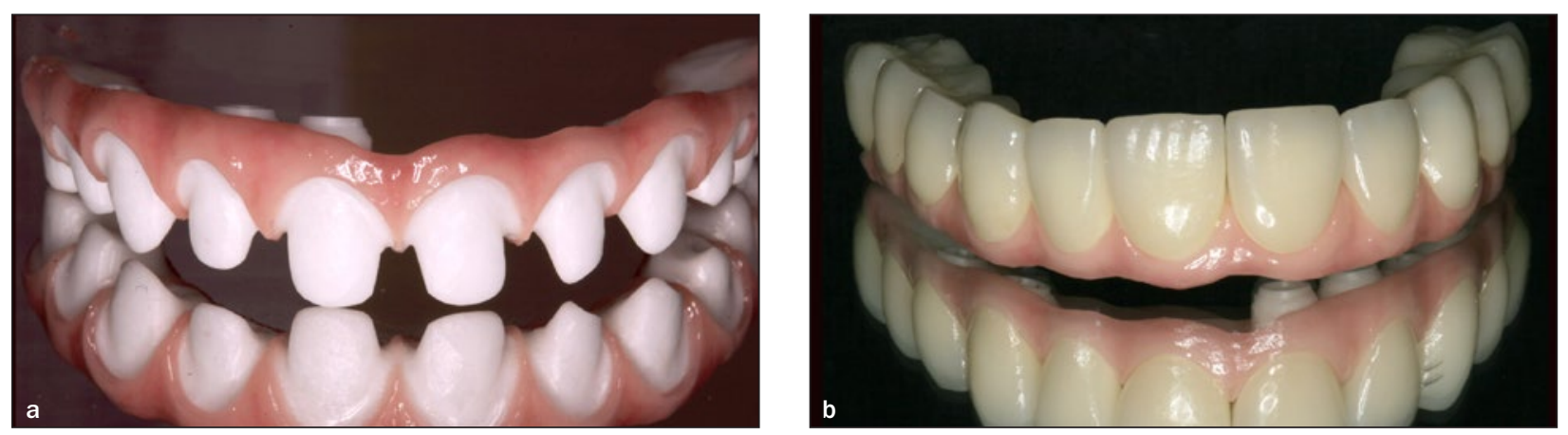


\begin{tabular}{|c|c|c|c|c|c|c|c|c|}
\hline \multirow[b]{2}{*}{$\mathbf{N}$} & \multicolumn{4}{|c|}{ Metal-acrylic } & \multicolumn{4}{|c|}{ Zirconia } \\
\hline & Arch & $\begin{array}{l}\text { Follow-up } \\
\text { duration } \\
\text { (mo) }\end{array}$ & $\begin{array}{c}\mathrm{N} \text { of } \\
\text { implants }\end{array}$ & $\begin{array}{c}\mathrm{N} \text { of } \\
\text { implants } \\
\text { with P-I }\end{array}$ & Arch & $\begin{array}{c}\text { Follow-up } \\
\text { duration } \\
(\mathrm{mo})\end{array}$ & $\begin{array}{c}\mathrm{N} \text { of } \\
\text { implants }\end{array}$ & $\begin{array}{c}\mathbf{N} \text { of } \\
\text { implants } \\
\text { with P-I }\end{array}$ \\
\hline 1 & Maxilla & 146 & 8 & 0 & Maxilla & 92 & 7 & 7 \\
\hline 2 & Maxilla & 129 & 6 & 1 & Maxilla & 67 & 6 & 0 \\
\hline 3 & Mandible & 156 & 5 & 1 & Mandible & 69 & 5 & 1 \\
\hline 4 & Mandible & 175 & 5 & 0 & Maxilla & 60 & 8 & 0 \\
\hline 5 & Maxilla & 82 & 6 & 2 & Mandible & 60 & 6 & 0 \\
\hline 6 & Mandible & 137 & 6 & 4 & Maxilla & 68 & 6 & 1 \\
\hline 7 & Mandible & 174 & 5 & 0 & Maxilla & 58 & 6 & 0 \\
\hline 8 & Maxilla & 86 & 5 & 5 & Mandible & 58 & 5 & 1 \\
\hline 9 & Mandible & 86 & 5 & 5 & Maxilla & 97 & 7 & 2 \\
\hline 10 & Maxilla & 95 & 8 & 6 & Maxilla & 123 & 8 & 0 \\
\hline 11 & Mandible & 93 & 5 & 1 & Maxilla & 104 & 8 & 0 \\
\hline 12 & Mandible & 154 & 6 & 0 & Mandible & 104 & 6 & 0 \\
\hline 13 & Maxilla & 66 & 6 & 0 & Maxilla & 132 & 6 & 2 \\
\hline 14 & Mandible & 284 & 5 & 0 & Mandible & 101 & 5 & 5 \\
\hline 15 & Maxilla & 125 & 7 & 1 & Mandible & 123 & 5 & 4 \\
\hline 16 & Mandible & 126 & 6 & 0 & Maxilla & 99 & 6 & 0 \\
\hline 17 & Mandible & 242 & 5 & 1 & Mandible & 98 & 5 & 0 \\
\hline 18 & Maxilla & 174 & 8 & 0 & Maxilla & 60 & 8 & 3 \\
\hline 19 & Mandible & 116 & 5 & 0 & Maxilla & 80 & 6 & 1 \\
\hline 20 & Maxilla & 174 & 6 & 0 & Mandible & 79 & 5 & 5 \\
\hline 21 & Maxilla & 73 & 6 & 3 & Maxilla & 132 & 8 & 1 \\
\hline 22 & Mandible & 60 & 5 & 0 & Mandible & 119 & 7 & 7 \\
\hline 23 & Mandible & 119 & 5 & 0 & Mandible & 116 & 5 & 0 \\
\hline 24 & Mandible & 92 & 5 & 0 & Maxilla & 63 & 7 & 2 \\
\hline 25 & Mandible & 92 & 5 & 0 & Mandible & 63 & 8 & 0 \\
\hline 26 & Maxilla & 80 & 8 & 2 & Maxilla & 105 & 6 & 0 \\
\hline 27 & Maxilla & 92 & 8 & 0 & Maxilla & 93 & 8 & 0 \\
\hline 28 & Mandible & 136 & 6 & 0 & Mandible & 93 & 7 & 0 \\
\hline 29 & Maxilla & 85 & 6 & 0 & Maxilla & 112 & 8 & 1 \\
\hline 30 & Mandible & 67 & 5 & 0 & Maxilla & 95 & 6 & 5 \\
\hline 31 & Maxilla & 98 & 6 & 2 & Mandible & 95 & 6 & 0 \\
\hline 32 & Mandible & 124 & 5 & 5 & 18 Maxilla & $90.9 \pm 23.49$ & 200 & 48 \\
\hline 33 & Mandible & 120 & 5 & 1 & 13 Mandible & & & $24 \%$ \\
\hline 34 & Maxilla & 107 & 6 & 3 & & & & \\
\hline 35 & Maxilla & 133 & 6 & 0 & & & & \\
\hline 36 & Mandible & 126 & 6 & 0 & & & & \\
\hline 37 & Maxilla & 120 & 6 & 1 & & & & \\
\hline 38 & Maxilla & 74 & 6 & 0 & & & & \\
\hline 39 & Mandible & 95 & 5 & 0 & & & & \\
\hline 40 & Maxilla & 91 & 6 & 1 & & & & \\
\hline 41 & Maxilla & 85 & 6 & 2 & & & & \\
\hline 42 & Maxilla & 60 & 5 & 0 & & & & \\
\hline \multirow[t]{3}{*}{43} & Maxilla & 125 & 7 & 0 & & & & \\
\hline & 22 Maxilla & $118 \pm 45.8$ & 252 & 47 & & & & \\
\hline & 21 Mandible & & & $18.6 \%$ & & & & \\
\hline
\end{tabular}


Copyright of International Journal of Oral \& Maxillofacial Implants is the property of Quintessence Publishing Company Inc. and its content may not be copied or emailed to multiple sites or posted to a listserv without the copyright holder's express written permission. However, users may print, download, or email articles for individual use. 